\title{
Localization of a Filamin-Like Protein in Glia of the Chick Central Nervous System
}

\author{
Vance Lemmon \\ Department of Anatomy and Cell Biology, and The Center for Neuroscience, \\ University of Pittsburgh, Pittsburgh, Pennsylvania 15261
}

\begin{abstract}
Monoclonal antibody 5 E10 binds to Muller cells in the chick retina and radial glia in the optic tectum. Biochemical and immunohistochemical experiments indicate that the $5 \mathrm{E10}$ antigen is related to, but may not be identical to, filamin, a high-molecular-weight, actin-binding protein. Developmental studies show that the $5 \mathrm{E} 10$ antigen is present in all neuroepithelial cells very early in development, but disappears by about Embryonic Day 10. These results suggest that neurons developmentally regulate not only the type of intermediate filament proteins they express, switching from vimentin to neurofilaments, but also the type of actin-binding proteins.
\end{abstract}

Filamin is a high-molecular-weight, actin-binding protein isolated from chicken gizzard (Wang et al., 1975). Similar proteins have been found in other types of cells, including macrophages (Hartwig and Stossel, 1975), HeLa cells (Weihing, 1982), and skeletal muscle (Gomer and Lazarides, 1981). Under appropriate conditions, actin and filamin combine to form a gel (Brotschi et al., 1978; Koteliansky et al., 1981). Immunohistochemical studies of a variety of cell types in culture have shown that filamin colocalizes with actin (Heggeness et al., 1977). Therefore, it has been suggested that filamin may play a role in shape changes, motility, and other mechanical activities of nonmuscle cells.

The distribution of filamin-like proteins in the CNS has not been widely studied, in contrast to that of spectrin-like proteins, a second class of high-molecular-weight, actin-binding proteins. It is well documented that the spectrin-like proteins, especially fodrin, and the various subunits that make up these proteins, are localized in neurons and their processes (Lazarides and Nelson, 1983; Levine and Willard, 1981). Fodrin is also present in glial cells (V. Lemmon, unpublished observations), although this is not well studied.

During development of the CNS, neurons and glia undergo cell migrations and develop processes that grow substantial distances. These cell movements require a mechanical force-generation system. As a result, it is of importance to determine if filamin-like proteins are present in neurons and glia, and if they are present at developmental stages where they could participate in the movement of cells and the outgrowth of axons or glial processes.

We have developed a monoclonal antibody, 5E10, that binds

Received Mar. 1, 1985; revised May 21, July 18, 1985; accepted July 23, 1985.

I would like to thank C. Snyder, J. Hailey, D. Willochell, and B. Stein for technical assistance, and C. Lagenaur and S. K. Lemmon for helpful discussions. I am also grateful to Drs. B. Granger, E. Lazarides, K. Wang, J. Glenney, and M. Willard for antisera, and to $P$. Linser for a prepublication copy of his paper. This work was supported by grants from the March of Dimes (5-395) and the National Fye Institute (EY05285)

Correspondence should be sent to Vance Lemmon, Ph.D., Department of Anatomy and Cell Biology, University of Pittsburgh, Pittsburgh, PA 15261.

Copyright $\odot 1986$ Society for Neuroscience $0270-6474 / 86 / 010043-09 \$ 02.00 / 0$ to a high-molecular-weight protein that colocalizes with actin in Muller cells of the retina. Based on cross-reactivity studies, this protein appears to be immunologically related to gizzard filamin. However, since the 5E10 antibody does not bind to smooth or skeletal muscle, its antigen may not be identical to smooth muscle filamin. We have used antibody $5 \mathrm{E} 10$ to study the developmental appearance of this protein in the chick nervous system and found that it is initially present in all cells in the developing nervous system, but rapidly becomes restricted to radial glia and Muller cells. Therefore, some glial cells in the chick nervous system contain a filamin-like protein. However, the absence of both $5 \mathrm{E} 10$ and gizzard filamin immunoreactivity from mature neurons indicates that they either do not contain a filamin-like protein or that, if they do, it is immunologically distinct from the species present in glia and smooth muscle.

\section{Materials and Methods}

Materials. White Leghorn chick embryos were incubated in a forced draft incubator maintained at $39^{\circ} \mathrm{C}$. The embryos were staged according to Hamburger and Hamilton (1951).

Tissue culture. Presumptive glial cells were prepared, using procedures based on those of Sensenbrenner and Mandel (1974) and Hanson et al. (1982). Retinas were removed from Embryonic Day 14 (E14) chick embryos and the pigmented epithelia and pecten removed. The tissue was then incubated for $30 \mathrm{~min}$ at $37^{\circ} \mathrm{C}$ in $0.125 \%$ trypsin in Hank's calcium, magnesium-free saline solution (CMF). Horse serum was then added to $10 \%$ and DNase to $0.05 \%$ prior to trituration of the tissue. This procedure produces single cells with a viability of greater than $95 \%$ based on trypan blue exclusion. The cells were then plated on tissueculture plastic in Dulbecco's modified Eagles Media (DMEM) $/ 10 \%$ fetal calf serum, containing penicillin/streptomycin/fungizone (Gibco) and incubated at $37^{\circ} \mathrm{C}$ in $5 \% \mathrm{CO}_{2}, 95 \%$ air, at $95 \%$ humidity. The use of E14 embryos as material for cultures causes neuronal cells to die, while flat cells proliferate and become confluent after about 1 week in culture.

Immunizations. Presumptive glial cells from cultures were used to immunize $\mathrm{Balb} / \mathrm{C}$ mice. Primary and secondary immunizations of 0.1 $\mathrm{ml}$ of packed cells were given intraperitoneally at the intervals of at least 4 weeks. Then, at least 4 weeks after the last immunization, two final boosts of $0.025 \mathrm{ml}$ of packed cells were given via the tail vein 4 and 2 d prior to sacrifice and spleen removal.

Fusion. Hybridomas were prepared with NS-1 myelomas using protocols described elsewhere (Lemmon et al., 1982). After screening, positive wells were cloned and recloned by limiting dilution until over $90 \%$ of the clones were positive. Cell stocks were then frozen in liquid nitrogen.

Screening and immunohistochemistry. An immunohistochemical screening procedure was used in order to select for glial-specific monoclonal antibodies. Retinas and optic tecta from E14 embryos were fixed with paraformaldehyde-lysine-periodate (PLP) (McLean and Nakane, 1974), cryoprotected with sucrose, and sectioned at $10-15 \mu \mathrm{m}$ in a cryostat. Hybridoma supernatants were incubated on the sections for $60 \mathrm{~min}$ at room temperature. The sections were then washed with PBS, pH 7.2, and incubated with a fluorescein-labeled goat-anti-mouse-IgG (Cappel Labs), diluted 1:200 in PBS/10\% horse serum (HS). Sections were examined using a Leitz epifluorescence microscope.

In order to conduct immunohistochemical studies of cells in culture, 


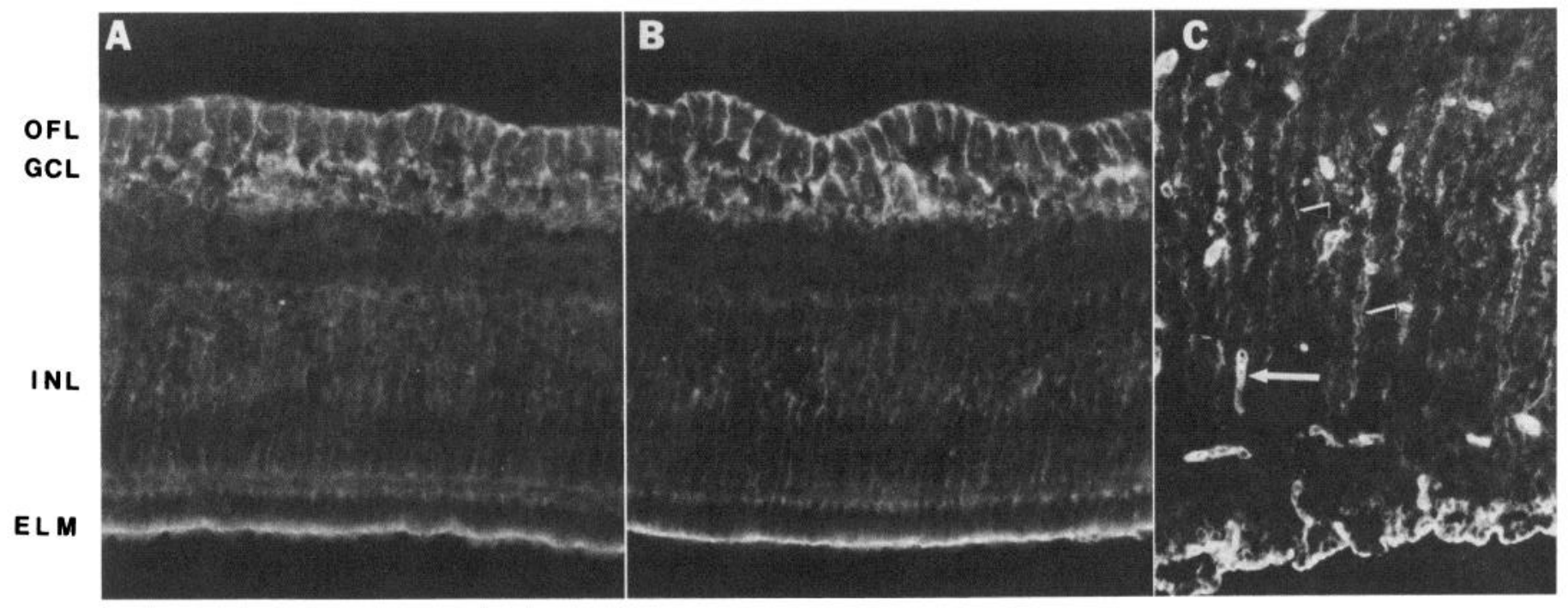

Figure 1. E14 retina and tectum stained with anti-filamin and 5E10. A, E14 retina stained with anti-smooth muscle filamin. Muller cell processes in the ganglion cell layer $(G C L)$ and optic fiber layer $(O F L)$ are well stained with the Muller cell somas in the middle of the inner nuclear layer, $(I N L)$ and endfeet at the external limiting membrane $(E L M)$ more weakly stained. $B$, An adjacent section stained with $5 E 10$ showing a pattern of staining that is similar to that in $A$. C, E14 optic tectum stained with $5 \mathrm{E} 10$. The arrowheads indicate radial processes of radial glia. The arrow indicates one of several blood vessels. Original magnification, $\times 250$.

cells were grown in $35 \mathrm{~mm}$ tissue culture dishes (as above), fixed with $2 \%$ paraformaldehyde/PBS for 10 min, extracted with $0.1 \%$ Triton X100/PBS for $10 \mathrm{~min}$, and then blocked with $10 \% \mathrm{HS} / \mathrm{PBS}$ for $10 \mathrm{~min}$. The cells were then stained with primary and secondary antibodies (as above). Material used in double-label experiments, whether cells in culture or sections, was stained with either a 1:200 dilution of rabbitanti-vimentin (obtained from B. L. Granger and E. Lazarides), a 1:200 dilution of anti-chicken-gizzard-filamin (a gift from K. Wang), or a 1:20 dilution of rhodamine-labeled phalloidin (Molecular Probes, Inc.).

Electron-microscopic immunohistochemistry. Eyes taken from embryos of various ages were fixed by overnight immersion at $4^{\circ} \mathrm{C}$ in PLP fixative. The eyes were then embedded in $2 \%$ agar and $1-2 \mathrm{~mm}$ sections were cut. The sections were blocked for $1 \mathrm{hr}$ with $10 \% \mathrm{HS} / \mathrm{PBS}$ and then incubated with the primary antibody overnight at $4^{\circ} \mathrm{C}$ on a rocker. Next, the sections were washed $4 \times$ with PBS over a $1 \mathrm{hr}$ period before being incubated with a biotin-labeled secondary antibody (Vectastain, Vector Labs) for $1 \mathrm{hr}$ at room temperature. The sections were again washed $4 \times$ and then incubated with avidin-biotin-HRP (ABC) complex (Vectastain, Vector Labs). After a final series of washes, the sections were reacted with diaminobenzidine/cobalt chloride/nickel ammonium sulfate solution (Adams, 1981). The sections were then post-fixed with osmium, dehydrated and embedded in Epon 812. Gold-colored sections were cut and examined using a Philips 300 electron microscope.

Immunohistochemical controls. Since it is not possible to perform absorption controls using antigen when conducting immunohistochemical studies using monoclonal antibodies to unknown antigens, other types of controls are required to show the specificity of the antibodies. For both light-microscopic studies and electron-microscopic studies two types of controls were always performed. The first was to process some sections of the tissue without incubating it with primary antibody but with the secondary antibody. This allowed us to determine if the secondary antibodies bound to the tissue. We found no binding of label, either fluorescein or HRP, in sections incubated only with secondary antibodies (Fig. 6). The second type of control was processing adjacent sections with monoclonal antibodies with different specificities. We routinely used antibodies that bind to different glial antigens (Lemmon, in press), ganglion cell antigens (Snyder et al., 1984), different photoreceptor antigens (V. Lemmon, unpublished observations), and neural cell adhesion molecule(N-CAM) (Lemmon et al., 1982; Rutishauser, 1984). By comparing sections that were incubated under identical conditions but with different antibodies, we were able to evaluate whether a given monoclonal antibody showed selectivity for a certain type of cell. For the double-label experiments conducted on cells in culture, a third type of control was required. Cells were incubated with one primary antibody (for example, the mouse monoclonal antibody, 5E10), which was then reacted with the secondary antibody (rabbit-anti-goat-IgG) used for the other primary antibody (the goat-anti-filamin). This allowed us to determine if the secondary antibodies bound only to the appropriatespecies IgG (Fig. 6). We have demonstrated elsewhere (Lemmon, in press) that the $\mathrm{N} 2$ and $\mathrm{I} 2$ filter cubes used in our Leitz microscope can adequately discriminate between fluorescein and rhodamine fluorescence.

Western blot analysis of antigens. Retinas were dissected clean of pigmented epithelium and pectin in CMF/0.2 mM phenylmethyl-sulfonylfluoride (PMSF). They were then transferred directly into sample buffer containing sodium dodecyl sulfate (SDS) and beta-mercaptoethanol (BME) and boiled for $5 \mathrm{~min}$. Samples were run on a $5-15 \%$ gradient gel with a $4.5 \%$ stack, using the buffer system of Laemmli (1973). After electrophoresis, the gel was divided into two portions. One was stained with silver (Mose-Lansen, 1981) or coomassie blue, while the other was electroblotted onto nitrocellulose paper (Towbin et al., 1979). The nitrocellulose paper was then cut into strips, one of which was stained with amido black to confirm the transfer of the proteins. The remaining strips were blocked with $10 \% \mathrm{HS} / \mathrm{PBS}$ for $1 \mathrm{hr}$ and then incubated at $4^{\circ} \mathrm{C}$ with primary antibodies overnight on a rocker. The $5 \mathrm{E} 10$ antibodycontaining supernatant was diluted $1: 20$ in $\mathrm{PBS} / 10 \% \mathrm{HS}$ for this purpose, while the anti-filamin was used at a dilution of 1:1000. The strips were then washed with PBS $/ 0.1 \%$ Tween 20 . The Vectastain ABC system and 4-chloro-1-napthol were used to visualize the location of the primary antibody. As a control, some strips were incubated only with the Vectastain secondary antibodies in $\mathrm{ABC}$ solution, to check for nonspecific binding.

Affinity purification. The $5 \mathrm{E} 10$ antibodies used to prepare an affinity column were purified from ascites fluid by ammonium sulfate precipitation and protein-A affinity chromatography (Ey et al., 1978). The antibodies were linked to Sepharose 4B (Pharmacia). Either E14 retinas or retinal flat cell cultures were homogenized in $20 \mathrm{~mm}$ Tris, $300 \mathrm{~mm}$ $\mathrm{KCl}, 0.5 \mathrm{~mm} \mathrm{MgCl}_{2}, 0.2 \mathrm{~mm}$ PMSF, $10 \mu \mathrm{g} / \mathrm{ml}$ turkey trypsin inhibitor (Sigma), pH 8.1. The homogenate was centrifuged at $16,000 \times g$ for 30 min and the supernatant run over a $0.5 \mathrm{ml}$ affinity column. After washing the column to remove nonspecifically bound material, the antigen was eluted by boiling the beads in SDS-containing sample buffer with betamercaptoethanol.

\section{Results}

We are interested in developing means of identifying glia in the early chick CNS. In order to accomplish this, we have produced monoclonal antibodies using various preparations of chick CNS as immunogens, and immunohistochemical procedures to identify glial-specific antibodies. As a means of enriching for glial antigens, we have prepared "flat cell" cultures from embryonic 


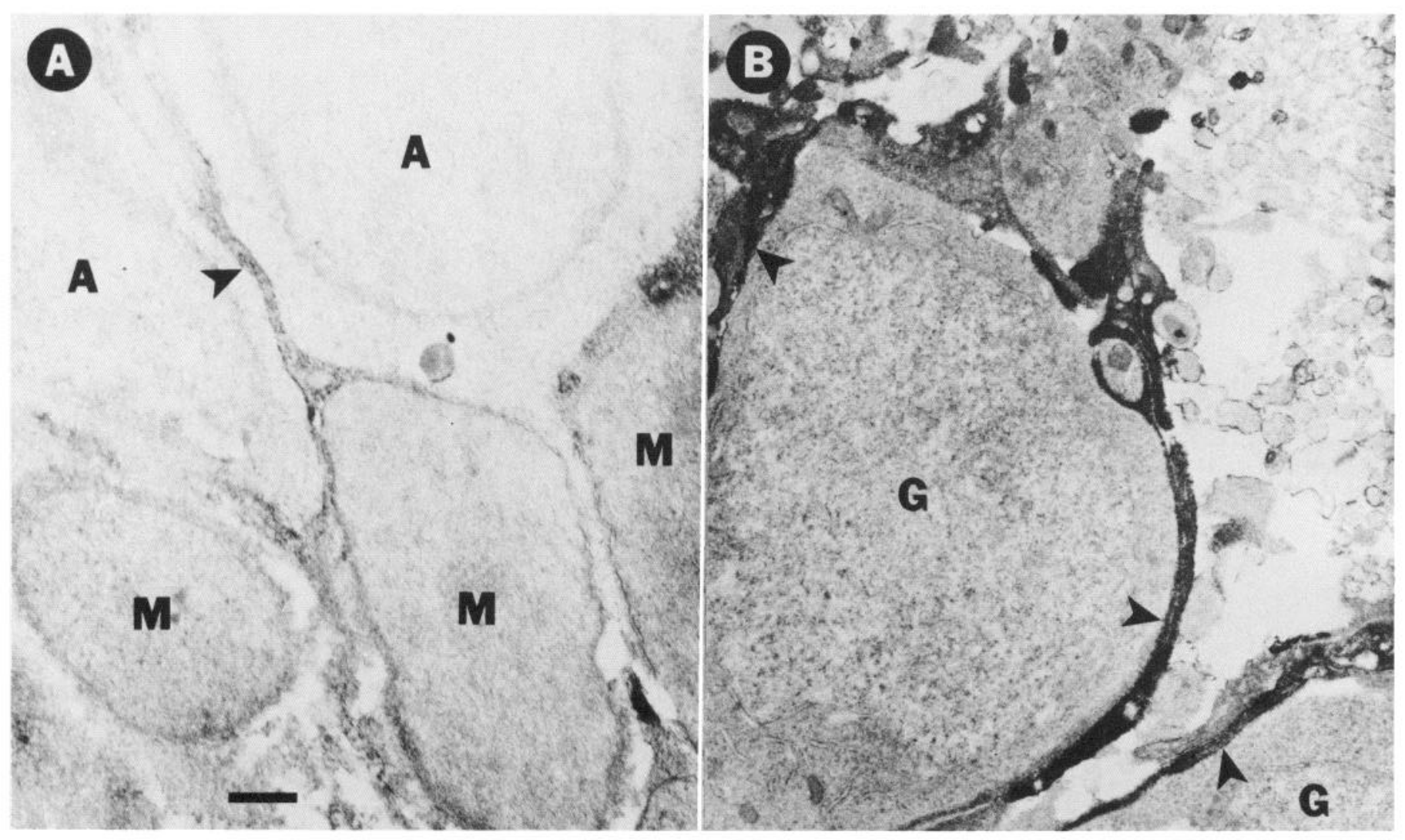

Figure 2. EM-immunohistochemistry of E14 retina with 5E10. $A$, Staining of the cytoplasm of three Muller cell somas $(M)$ with one process (indicated by the arrowhead) passing between two amacrine cell somas $(A)$ in the inner nuclear layer. $B$, Staining of Muller cell processes $($ arrowheads) surrounding the somas of two ganglion cells $(G)$. Scale bar $=1 \mu \mathrm{m}$.

chick retinas. Similar cultures have been used by others to study neuron-glial adhesion (Grumet et al., 1983) and have been shown to contain the glial proteins, glutamine synthetase and carbonic anhydrase (Moscona and Linser, 1983). Hybridoma supernatants were screened on sections of E14 retina and optic tectum. Hybridomas producing antibodies specific for glia were cloned. This report describes observations made concerning 5E10, one of the monoclonal antibodies we have produced.

\section{Immunohistochemical studies on embryonic tissues}

In E14 embryos, antibody 5E10 binds to Muller cells in the retina and to radial glia in the optic tectum, while it does not bind to neurons. The antigen appears, in the light microscope, to be present throughout Muller cells (Fig. 1). Staining is especially prominent in the middle of the inner nuclear layer (INL), where the somas of the Muller cells are located; in the Muller cell endfeet, both at the inner limiting membrane (ILM) and the outer limiting membrane (OLM); and in the ganglion cell layer (GCL). In the optic tectum, the antigen is present in the somas of the radial glia that line the ventricle. The antigen is also present in the processes of the radial glia in the inner half of the tectum, having a beaded appearance within the processes. In addition, the 5E10 antibody binds to vascular endothelial cells in the tectum.

Electron-microscopic (EM) immunohistochemistry was conducted on E14 and E19 retinas in order to confirm that the $5 \mathrm{E} 10$ antigen was within Muller cells in regions of the retina that contained processes of more than one cell type. Muller cells are characterized by their endfeet at the ILM and OLM, and by the location of their somas in the middle of the INL. Throughout the retina, the $5 \mathrm{E} 10$ antigen was found to be localized within the Muller cells, and was not present in neurons or their pro- cesses. The immunostain in Muller cells appeared to be uniformly and diffusely distributed throughout the cytoplasm. Figure 2 shows examples of Muller cell processes in the GCL and INL that demonstrate $5 \mathrm{E} 10$ immunoreactivity.

Studies of the developmental distribution of the $5 \mathrm{E} 10$ antigen indicate that it is present in virtually all cells of the early embryo (E6), becoming restricted to fewer cell types with increasing age (Fig. 3). In the retina, most cells appear to be 5E10-positive until about E9. By E10, the antigen appears to be restricted to a subset of cells extending from the ILM to the OLM, which suggests that they are Muller cells. Examination of sections of retinas from all later stages (including adult) revealed that the antigen is restricted to Muller cells. In the tectum, a similar pattern is seen: the antigen apparently is in all cells preceding E10, and is restricted to radial glia and blood vessels at later times. Astrocytes, which appear in the stratum album centrale and the stratum opticum (Linser, 1985), do not stain with this antibody.

In examining a variety of tissues at E14, 5E10-positive staining was found in vascular endothelia throughout the embryo, in cartilage cells, in lens cells and pigmented epithelia of the eye, and in skin epithelia. No staining of skeletal muscle or hepatocytes was observed. Examination of E19 gizzard and E14 intestine demonstrated 5E10 immunoreactivity in intestinal epithelia, but not in smooth muscle. This contrasts with antigizzard filamin, which binds to both smooth muscle and intestinal epithelia (Fig. 4).

\section{Cell culture studies}

Flat cell cultures were prepared from E14 retina and used for immunohistochemical studies. When live, unfixed cells were incubated with 5E10 antibody, there was no detectable staining 


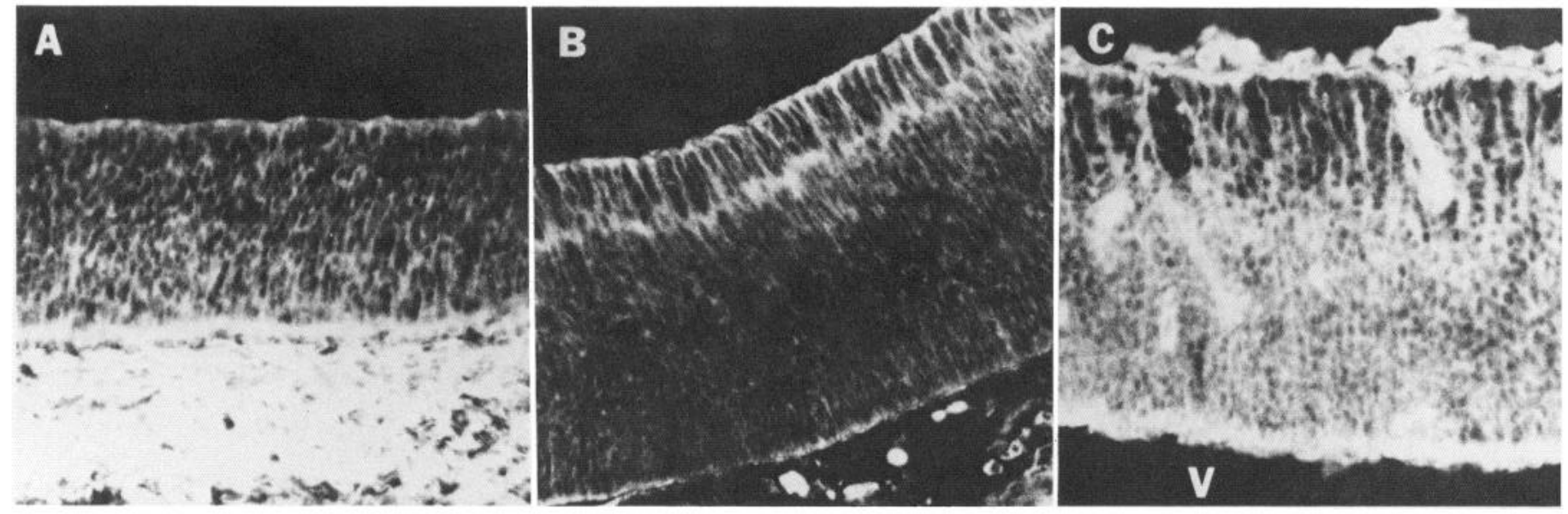

Figure 3. 5E10 localization in early retina and tectum. $A$, E6 retina has $5 \mathrm{E} 10$ immunoreactivity in apparently all cells. The developing sclera below the retina is very strongly stained. $B$, E9 retina shows less $5 \mathrm{E} 10$ immunoreactivity, with staining becoming restricted to Muller cell processes. $C$, E6 tectum has strong $5 \mathrm{E} 10$ immunoreactivity in the neuroepithelium adjacent to the ventricle $(V)$, while only radial processes appear stained in the more superficial, cell-free region. Original magnification, $\times 250$.

of cells, suggesting that the antigen is not present on the cell surface. When the cells were fixed, either with paraformaldehyde or cold $95 \% \mathrm{EtOH}$, a filamentous network was stained within the flat cells. The most obvious feature of this network was the prominent fiber bundles extending from one side of the cell to the other. Cells with small, round somas and fine neuritic processes, which are strongly positive for N-CAM (Lemmon et al., 1982; Rutishauser et al., 1978), as well as tetanus toxin (Pett-

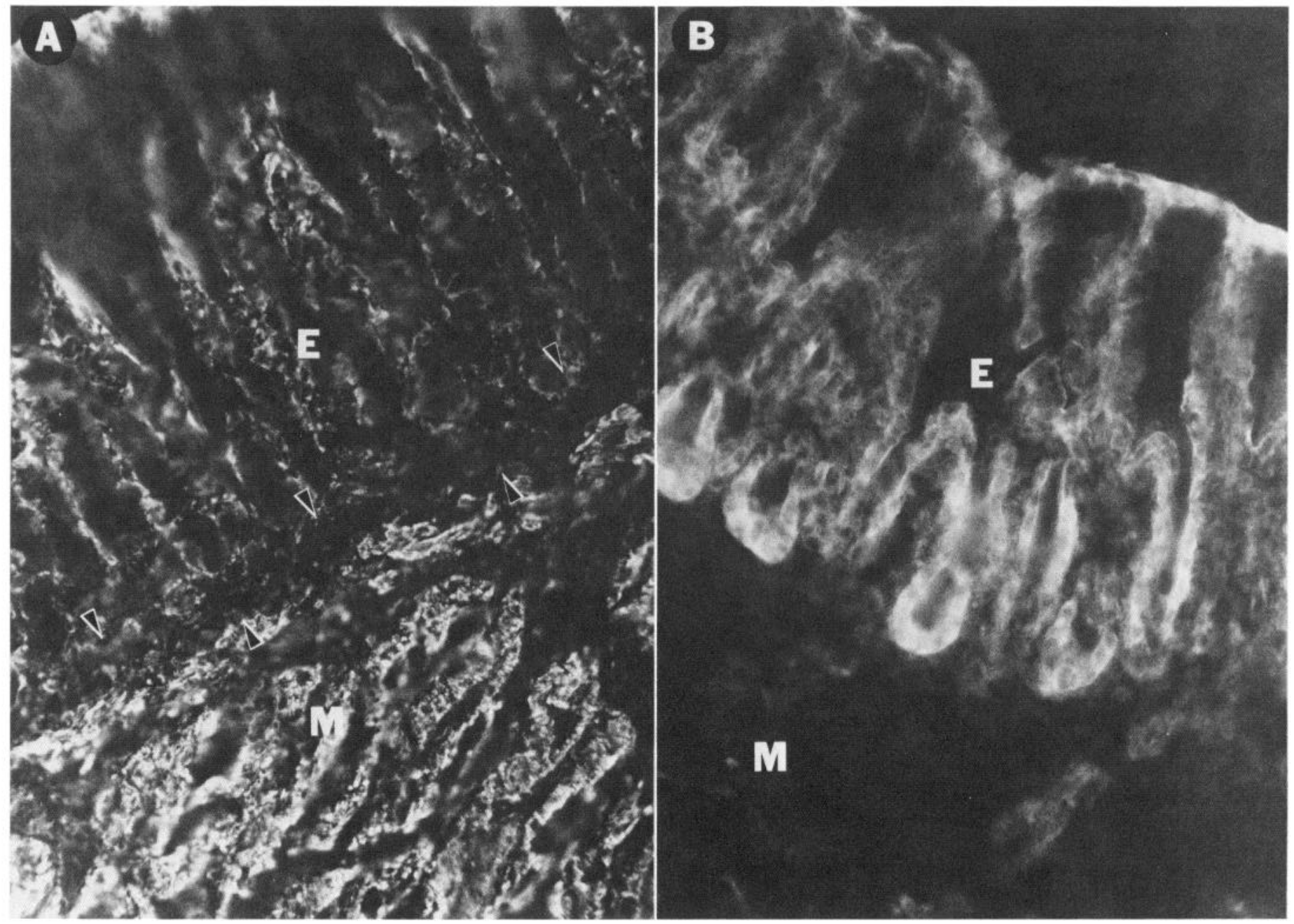

Figure 4. E19 gizzard. A, Anti-smooth muscle filamin stained both the smooth muscle $(M)$ and epithelial cells $(E)$ in the gizzard. $B$, 5 E10 stained only the epithelial cells and not the smooth muscle cells. Original magnification, $\times 250$. 

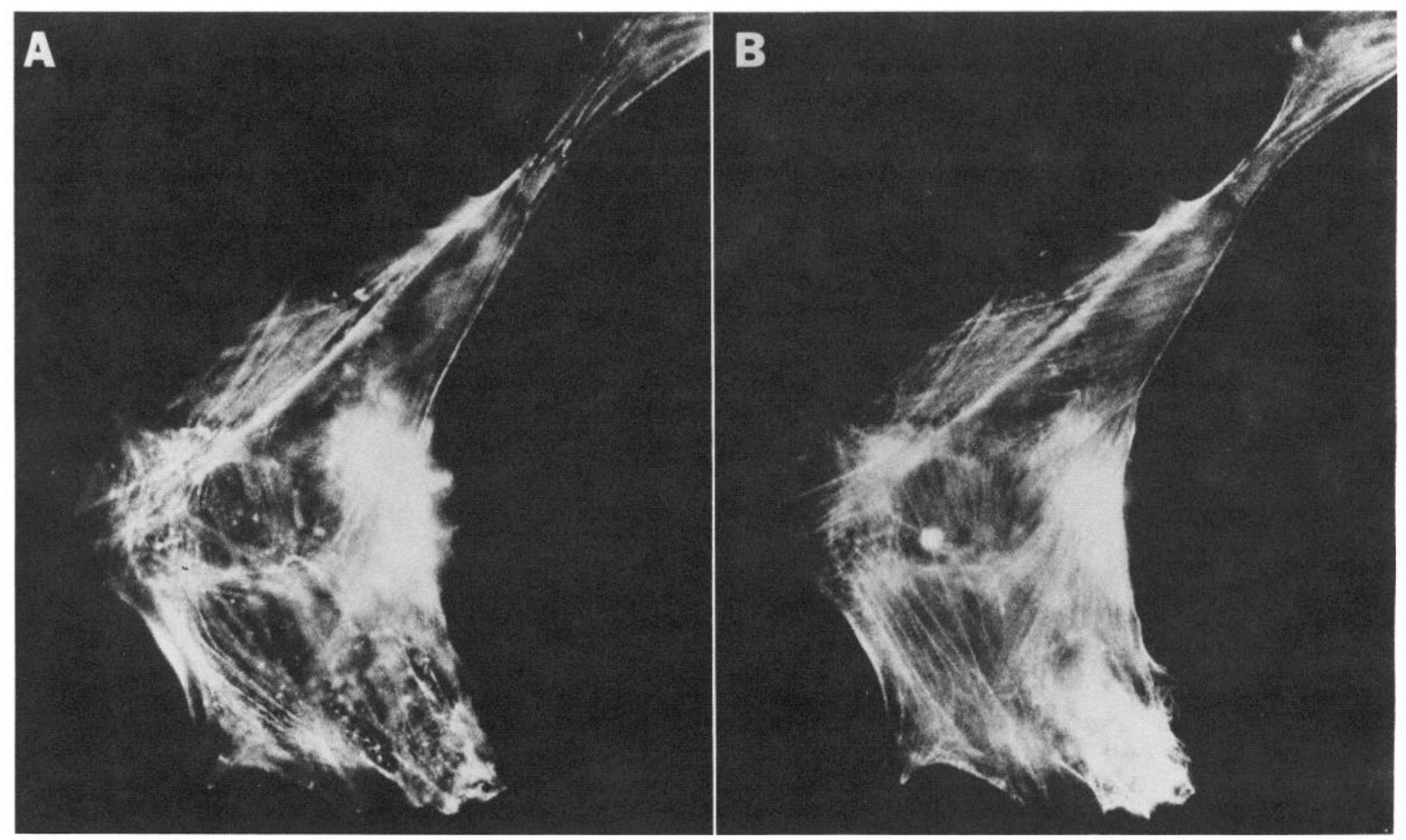

Figure 5. $5 \mathrm{E} 10$ and phalloidin double-label study of flat cells from E14 retina in culture for $48 \mathrm{hr}$. $A$, Flat cell stained with $5 \mathrm{E} 10$ showing staining of stress fibers. $B$, The same flat cell as in $A$ stained with phalloidin, showing a pattern similar to that of $5 \mathrm{E} 10$. Original magnification, $\times 500$.

mann et al., 1979), and, therefore, are presumed to be neurons, were not stained by $5 \mathrm{E} 10$. In double-label experiments, it was found that the pattern of staining of $5 \mathrm{E} 10$ in flat cells was similar to that obtained with phalloidin (Fig. 5), indicating that the $5 \mathrm{E} 10$ antigen might be present in association with actin (Amato et al., 1983; Wulf et al., 1979). Similar double-label experiments demonstrated that the $5 \mathrm{E} 10$ antigen is not associated with intermediate filaments visualized with an anti-vimentin antibody (data not shown).

Based on the information that the $5 \mathrm{E} 10$ antigen is immunologically related to smooth muscle filamin (see below), a second series of double-label experiments were conducted. E14 flat cell cultures were stained, first, with the 5E10 antibody, then with goat anti-smooth muscle filamin. The cultures were then stained with rhodamine-labeled rabbit anti-mouse-IgG (r-RaM) and fluorescein-labeled rabbit anti-goat-IgG (f-RaG). The staining pattern that was observed was very similar to, if not identical with, the two primary antibodies (Fig. 6, $a, b$ ). Control experiments demonstrated that the r-RaM did not bind to the goat primary antibody (Fig. $6, g, h$ ) and that the f-RaG did not bind to the 5E10 antibody (Fig. 6, d,e). When flat cells were incubated only with the secondary antibodies, there was no labeling of the cells (Fig. 6, $j, k$ ). Additional controls performed, but not shown, demonstrated that, when flat cells were incubated with $5 \mathrm{E} 10$ followed by both r-RaM and $\mathrm{f}-\mathrm{RaG}$, staining was detected only with rhodamine filters, indicating that the $\mathrm{f}-\mathrm{RaG}$ did not bind to the r-RaM. In the converse experiment, using anti-filamin and both secondary antibodies, only fluorescein labeling was observed. These controls demonstrate the specificity of the secondary antibodies for the appropriate primary antibody.

The immunohistochemical studies of early (E6-8) retina indicated that most, if not all, cells contained the 5E10 antigen. However, since the retina is relatively undifferentiated at these stages, it is conceivable that a small percentage of differentiated neurons, lacking the antigen, might be obscured by the many undifferentiated cells. In order to determine whether the $5 \mathrm{E} 10$ antigen was present or absent in neurons, cultures of dissociated retinal cells were prepared at E6 and 10. The cultures were incubated for $18 \mathrm{hr}$, then fixed and stained with $5 \mathrm{E} 10$. The cultures of E6 cells contained typical flat cells and small round cells with neuritic processes. All these cells were positive for the $5 \mathrm{E} 10$ antigen; this was particularly prominent in neuritic processes (Fig. 7). Staining of sister cultures after $36-48 \mathrm{hr}$ in culture with anti-N-CAM antibodies indicated that the small round cells were strongly positive for N-CAM, suggesting that they are neurons. It was necessary to culture the cells for this longer period in order for the N-CAM to reappear on the surface of the cells following trypsinization (Rutishauser et al., 1978). However, after this longer time in culture, the cells expressing $\mathrm{N}-\mathrm{CAM}$ were no longer positive for the $5 \mathrm{E} 10$ antigen. In the cultures of E10 retinas, only the flat cells contained the 5E10 antigen.

\section{Biochemical studies}

Two separate analyses were performed in order to biochemically characterize the $5 \mathrm{E} 10$ antigen. Immunoblots, using either retina (Fig. 8) or flat cells from cultured retina, yielded identical patterns, indicating that the $5 \mathrm{E} 10$ antibody binds to a protein with an apparent $M_{r}$ of about $250 \mathrm{kDa}$. Occasionally, bands of lower molecular weights were observed; but the intensity and number of these bands decreased when protease inhibitors were included during the early steps of cell preparation, indicating that they were the result of degradation of the major band. The determination of a precise molecular weight for the $5 \mathrm{E} 10$ antigen is difficult with SDS-PAGE. However, on Western blots of whole 

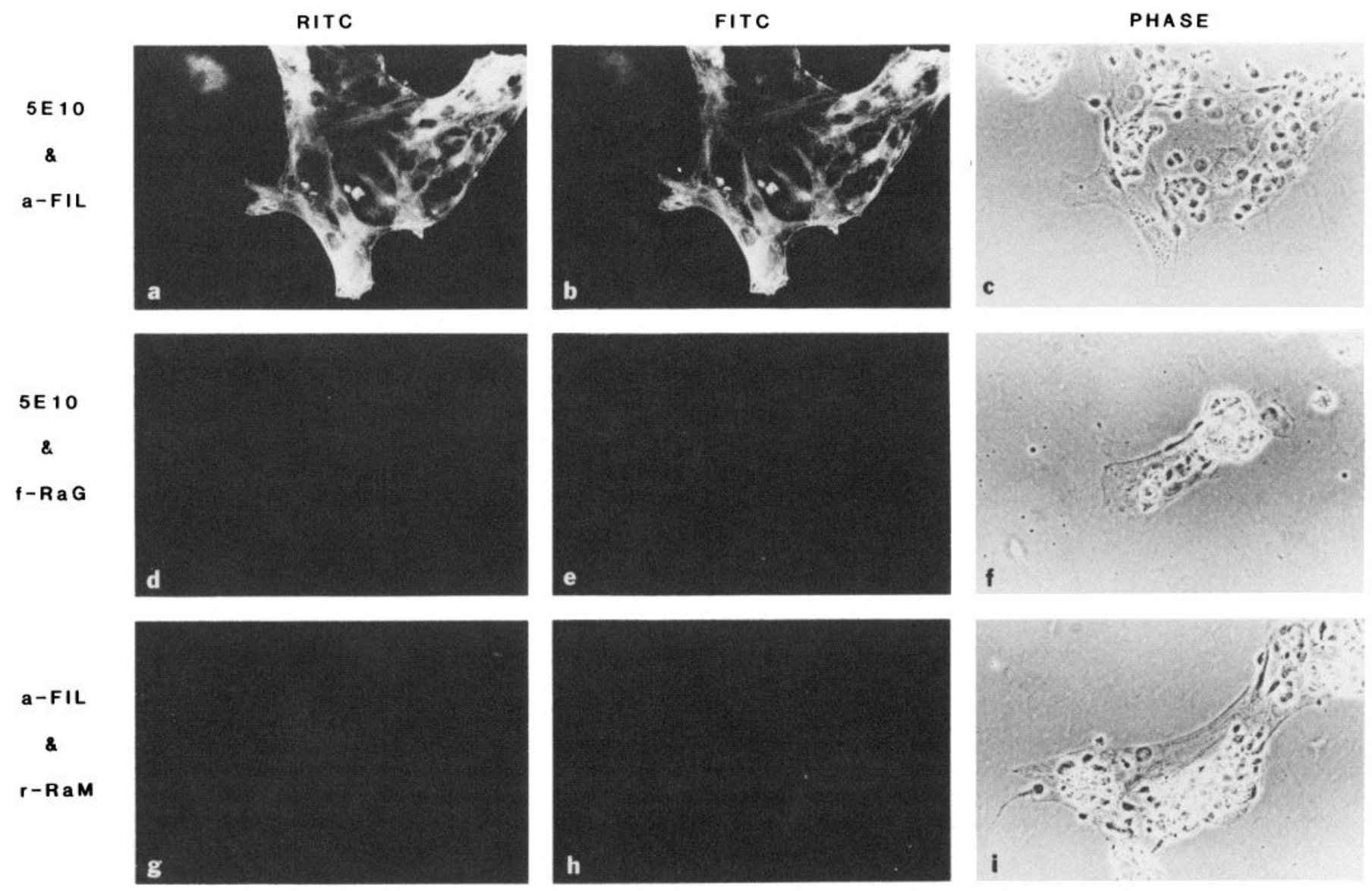

NO

PRIMARY
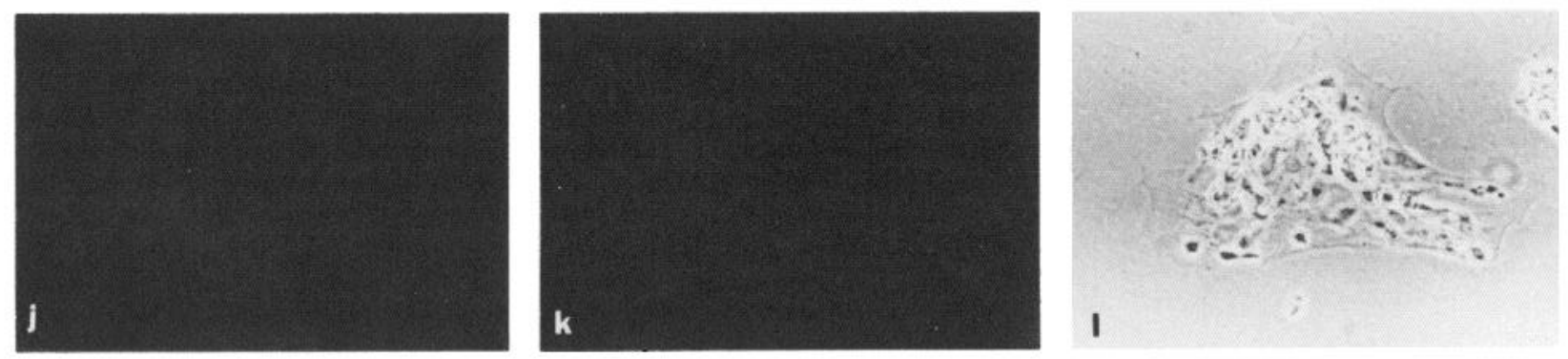

Figure 6. 5E10 and anti-smooth muscle filamin ( $a$-Fil) double-label study of E14 flat cells in culture $72 \mathrm{hr}$. See text. $a, d, g$, and $j$, Viewed with filters for rhodamine (RITC) fluorescence. $b, e, h$, and $k$, Viewed with filters for fluorescein (FITC) fluorescence. $c, f, i$, and $l, P h a s e$ image of the fields corresponding to the fluorescence photos. $a, 5 \mathrm{E} 10$ + rhodamine rabbit anti-mouse IgG (r-RaM). $b, a-F i l+$ fluorescein rabbit anti-goat IgG (f-RaG). $c$, Phase image corresponding to $a$ and $b . d, e$, and $f$, Demonstration that the $\mathrm{f}-\mathrm{RaG}$ did not bind to 5E10. $g$, $h$, and $i$, Demonstration that the r-RaM did not bind to a-Fil. $j, k$, and $l$, Demonstration that the r-RaM and f-RaG did not stain flat cells when there were no primary antibodies. Original magnification, $\times 250$.

retina, the $5 \mathrm{E} 10$ antigen was closer in molecular weight to TW260 than to chicken-fodrin-235 (Glenney et al., 1982) (data not shown).

Immunoaffinity purifications of the $5 \mathrm{E} 10$ antigen from flat cell cultures or from retina gave results similar to the immunoblot analysis, with a $250 \mathrm{kDa}$ protein being bound to the column. It appears that the $5 \mathrm{E} 10$ antibody binds to the antigen under a wide variety of conditions, since $0.2 \mathrm{M}$ glycine, $0.6 \mathrm{M}$ $\mathrm{NaCl}, \mathrm{pH} 2.5,0.05 \mathrm{M}$ diethylamine, $0.5 \mathrm{M} \mathrm{NaCl}, \mathrm{pH} 11.5$, and $4 \mathrm{M} \mathrm{MgCl}_{2}, \mathrm{pH} 7.5$, all failed to elute antigen from the immunoaffinity columns. The antigen could be eluted with $2.5 \%$ SDS, $0.2 \mathrm{M}$ Tris, $\mathrm{pH} 6.8$. However, the most effective means of eluting the antigen was to boil the affinity beads with bound antigen in sample buffer containing SDS and BME. This also removed some of the heavy and light chains of IgG's from the beads. In an attempt to determine the biochemical identity of the 5E10 antigen, Western blot analysis was performed, using affinity purified antigen and antibodies against chicken gizzard filamin, chicken fodrin, spectrin, and TW-260. Of these four, only the anti-gizzard filamin showed any binding to the $5 \mathrm{E} 10$ antigen (Fig. 9). In this figure, the horse-anti-mouse-IgG secondary antibody, used to visualize the $5 \mathrm{E} 10$ antibody on the Western blot (lane E), also bound to the IgG fragments eluted from the beads (lane D). The horse anti-goat IgG secondary antibody used to visualize the goat anti-filamin antibody showed little cross-reactivity with the mouse IgG fragments (lane C).

\section{Discussion}

Several actin-binding proteins that share biochemical and immunological properties have been described. These include chicken-gizzard filamin (Wang et al., 1975), macrophage actinbinding protein (Hartwig and Stossel, 1975), HMWP from HeLa 


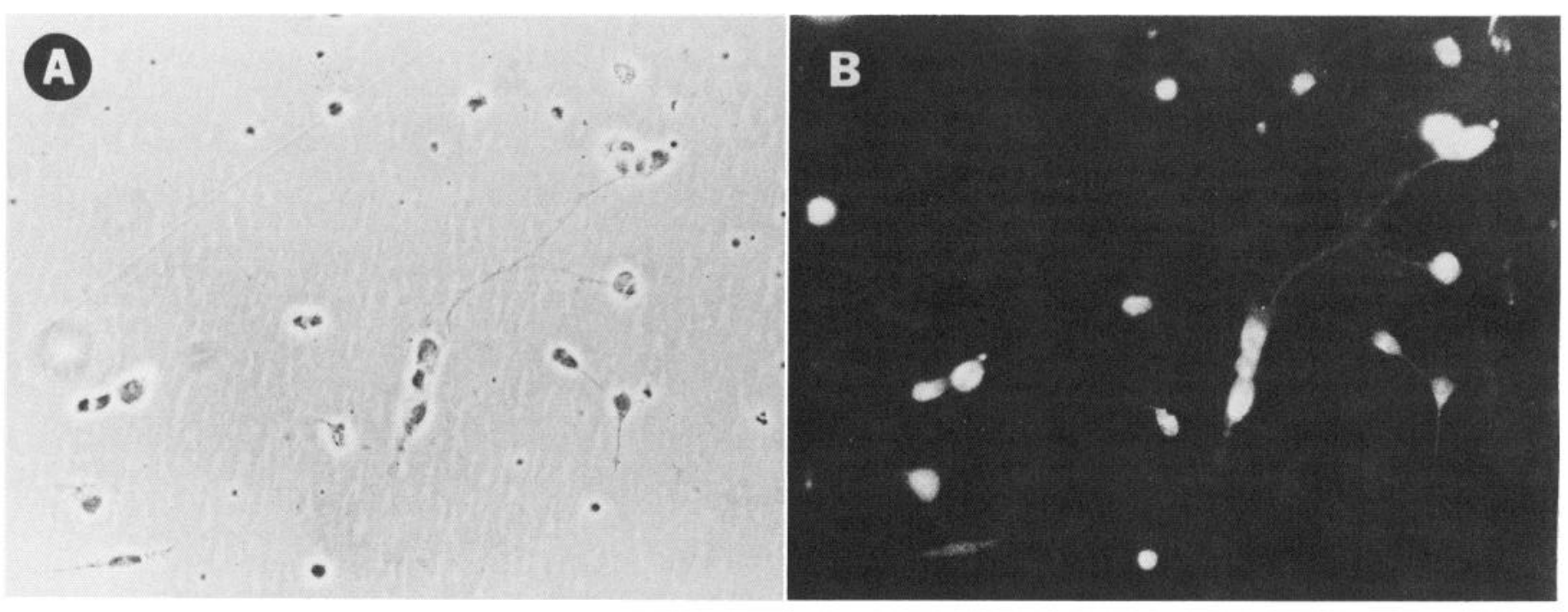

Figure 7. E6 retinal cells in culture for $18 \mathrm{hr}$. $A$, Phase photograph demonstrating location of cells and their processes. $B, 5 \mathrm{E} 10$ staining of cells indicates that apparently all cells, including those with neuronal morphology, contain the 5E10 antigen in the E6 retina. Original magnification, $\times 250$.

cells (Weihing, 1982), and skeletal muscle filamin (Gomer and Lazarides, 1981, 1983). Mangeat and Burridge (1983) have also reported two different forms of filamin in gizzard based on differences in binding to phosphocellulose. The various filaminlike proteins bind to F-actin filaments to form a gel (Brotschi et al., 1978). Immunohistochemical studies have localized them in the leading and ruffling edges of migrating cells in culture, and in stress fibers in stationary cells (Couchman et al., 1983; Heggeness et al., 1977). These and other experiments have resulted in a hypothesis suggesting that filamin cross-links actin in the cortical cytoplasm and that the control of this process by calcium-sensitive and calcium-insensitive proteins plays an important role in regulating cell motility and cytoplasmic movement (Stossel et al., 1981).

Antibody 5E10 binds to a protein with an apparent $M_{r}$ of about $250 \mathrm{kDa}$ that is present in Muller cells in the retina and radial glia in the optic tectum. While the $5 \mathrm{E} 10$ antibody does not bind to mature neurons, smooth muscle, or skeletal muscle, it does bind to a number of other cell types, including vascular endothelia, intestinal epithelia, and cartilage cells. In cultured retinal flat cells, the antigen is present in association with actin filaments, suggesting that the molecule may be an actin-binding protein. Our experiments, in which affinity-purified $5 \mathrm{E} 10$ antigen was shown to bind anti-gizzard filamin antibodies, indicate that the antigen is related to gizzard filamin. Subsequent immunohistochemical studies of chicken retina with the goat-antigizzard-filamin antibody show staining of Muller cells, but not of neurons. Also, double-label studies of flat cells in culture with $5 \mathrm{E} 10$ and anti-gizzard filamin demonstrated patterns that are difficult to distinguish. However, since the 5E10 antibody does not bind to muscle, it may be different from gizzard-filamin (Wang et al., 1975) or skeletal filamin (Gomer and Lazarides, $1981,1983)$. The possibility remains that the $5 \mathrm{E} 10$ antigenic determinant is present in muscle cells but is sequestered in some fashion. At the present time, the relationship of the $5 \mathrm{E} 10$ antigen, either to HMWP (Weihing, 1982) or macrophage actinbinding protein (Hartwig and Stossel, 1975), is unknown. To the best of my knowledge, this is the first report that a filaminlike protein is present in some types of CNS glia and is not present in mature neurons. Filamin-immunoreactivity has previously been found in support cells from peripheral nerve ganglia (Wang et al., 1975) and in Schwann cells (Shaw et al., 1981).

Muller cells have a very unusual morphology when compared with other glial cells, such as astrocytes or oligodendrocytes. One characteristic of Muller cells is that they produce large sheets of membranes that surround and separate neuronal somas from one another. This is especially obvious in the ganglion cell

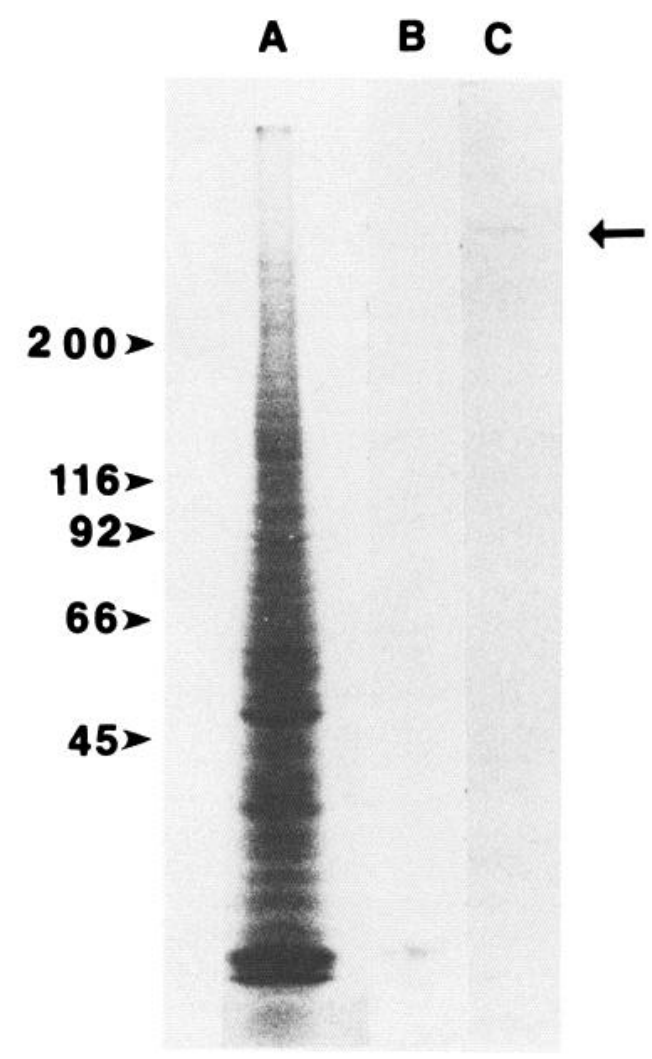

Figure 8. Western blot analysis of E10 retina using 5E10 antibody. One E10 retina was boiled directly in $250 \mu \mathrm{l}$ of SDS sample buffer. Five microliters were loaded in each lane of a $5-15 \%$ gradient gel. Lane A, A coomassie blue stain of whole E10 retina. $B$, Transfer incubated only with Vectastain secondary antibody and $\mathrm{ABC}$ solution. $C$, Transfer stained with a 1:20 dilution of 5 E10 supernatant for $60 \mathrm{~min}$ and then Vectastain. The arrow indicates the location of the 5E10 antigen. 


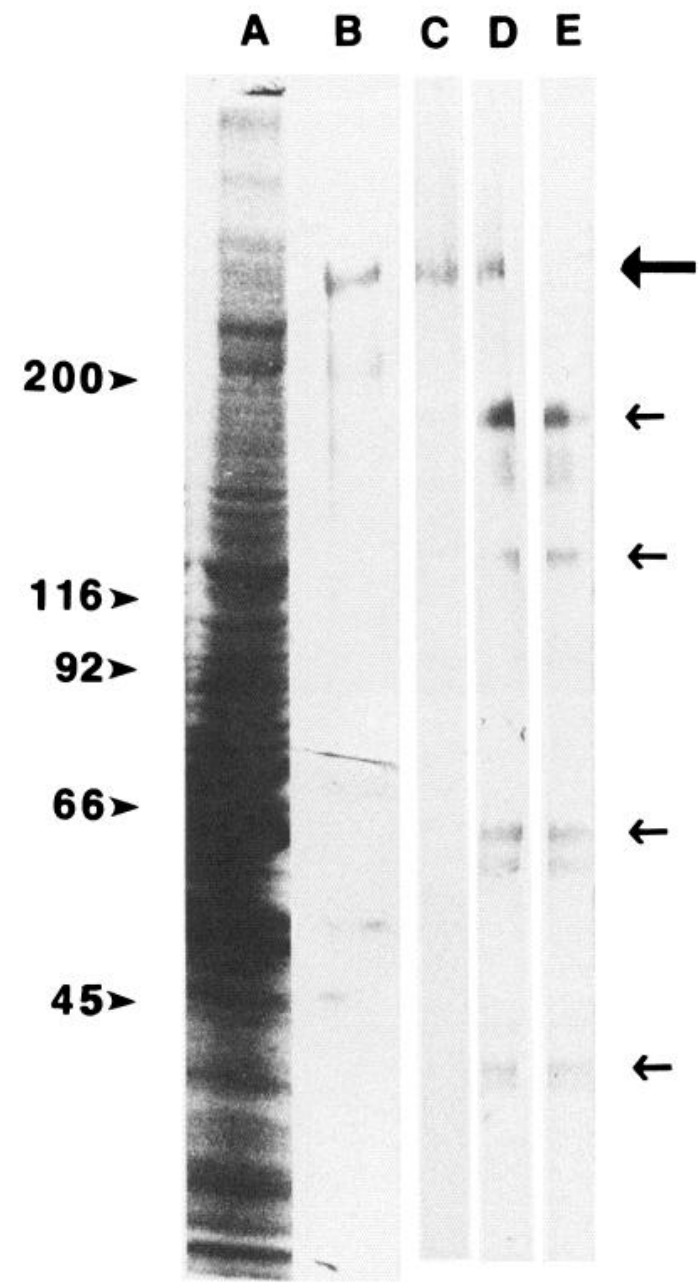

Figure 9. Affinity purification and Western blot analysis of $5 \mathrm{E} 10$ antigen. Lane $A$, The Coomassie blue stain of the starting material run through the $5 \mathrm{E} 10$ affinity column. $B$, A silver stain of the material eluted from the $5 \mathrm{E} 10$ affinity column using SDS sample buffer. $C, D$, and $E$, The eluate from the affinity column was run on SDS-PAGE, transferred to nitrocellulose paper, and then reacted with different antibodies. In $C$, goat anti-smooth muscle filamin bound to the 5E10 antigen (large arrow). $D$, Binding of the $5 \mathrm{E} 10$ antibody to the $5 \mathrm{E} 10$ antigen (large arrow). Lane $E$ was not incubated with a primary antibody, but with a horse anti-mouse IgG; it demonstrates that the lower molecular weight bands (small arrows) in $D$ and $E$ are due to the mouse IgG's that were eluted from the affinity beads. In $C$, these bands were not detected by the horse anti-goat $\mathrm{IgG}$ secondary antibody.

layer. In these regions, the amount of cytoplasm separating one side of a cell process from the other is very small, the two membranes being only $0.2-0.3 \mu \mathrm{m}$ apart. Since our immunohistochemical studies suggest that the amount of filamin in these regions is relatively high, it is possible that the filamin-actin gel is functioning to maintain the shape of the Muller cell processes that are isolating the neuronal somas.

Despite the recent revolution in immunological approaches to studying the nervous system, there remain relatively few well characterized markers for glia in the very early brain. Widely used markers such as glial fibrillary acidic protein and S-100 are not present in glia in all species at early developmental stages. At the present time, an intermediate filament protein, vimentin, appears to be the best-described marker for glia in the early CNS (Tapscott et al., 1981). Vimentin is present within all cells in the very early chick CNS, disappearing from neurons with development, and becoming restricted to Muller cells and radial glia as does the 5E10 antigen (Lemmon and Rieser, 1983; Tapscott et al., 1981). The 5E10 antigen shares another characteristic with vimentin that prevents it from being a definitive marker for glia in tissue culture studies: both are present in blood vessels, as well as in a number of other tissues. Finally, these proteins are intracellular, which prevents them from being useful markers in experiments that require that the marker be on the cell surface.

The absence of 5E10 and gizzard-filamin-immunoreactivity from mature neurons suggests that neurons may switch from one type of filamin to another as they differentiate from neuroepithelial cells. This would not be unprecedented, since neurons in the chick switch from the production of vimentin very early to that of neurofilaments later (Tapscott et al., 1981), and skeletal muscle cells switch from one type of filamin to another as the mature (Gomer and Lazarides, 1983). However, since high-molecular-weight, actin-binding proteins from brain have been widely studied and found to consist mostly of spectrinlike molecules (Lazarides and Nelson, 1983), it is possible that mature neurons do not contain a filamin-like protein.

The 5E10 immunoreactivity disappears from most cells in the developing retina (E8-E10) slightly later than the time when most neurons are undergoing their final mitotic division (E3$\mathrm{E} 8 ; \mathrm{Kahn}, 1974)$. It is likely that, as neurons become postmitotic and begin to differentiate, some change occurs that results in their loss of 5E10 immunoreactivity. However, the fact that Muller cells in the adult chicken retina retain 5E10 immunoreactivity indicates that the $5 \mathrm{E} 10$ antigen is not limited to cells undergoing mitosis.

Antibody $5 \mathrm{E} 10$ should be a very useful reagent for studying the localization and biochemistry of its filamin-like antigen, since it binds to the antigen after a variety of fixation procedures and can be used to obtain highly enriched antigen with a simple affinity-purification method.

\section{References}

Adams, J. (1981) Heavy metal intensification of DAB-based HRP reaction product. J. Histochem. Cytochem. 29: 775.

Amato, P. A., E. R. Unanue, and D. L. Taylor (1983) Distribution of actin in spreading macrophages: A comparative study on living and fixed cells. J. Cell Biol. 96: 750-761.

Brotschi, E. A., J. H. Hartwig, and T. P. Stossel (1978) The gelation of actin by actin-binding protein. J. Biol. Chem. 253: 8988-8993.

Couchman, J. R., R. A. Badley, and D. A. Rees (1983) Redistribution of microfilament-associated proteins during the formation of focal contacts and adhesions in chick fibroblasts. J. Mus. Res. Cell Motil. 4: 647-661.

Ey, P. L., S. J. Prowse, and C. R. Jenkin (1978) Isolation of pure $\mathrm{IgG}_{1}$, $\mathrm{IgG}_{2 \mathrm{a}}$ and $\mathrm{IgG}_{2 \mathrm{~b}}$ immunoglobulins from mouse serum using protein A-sepharose. Immunochemistry 15: 429-436.

Glenney, J. R., P. Glenney, and K. Weber (1982) Erythroid spectrin, brain fodrin, and intestinal brush border proteins (TW-260/240) are related molecules containing a common calmodulin-binding subunit bound to a variant cell type-specific subunit. Proc. Natl. Acad. Sci. USA 79: 4002-4005.

Gomer, R. H., and E. Lazarides (1981) The synthesis and deployment of filamin in chicken skeletal muscle. Cell 23: 524-532.

Gomer, R. H., and E. Lazarides (1983) Switching of filamin polypeptides during myogenesis in vitro. J. Cell Biol. 96: 321-329.

Grumet, M., U. Rutishauser, and G. M. Edelman (1983) Neuron-glia adhesion is inhibited by antibodies to neural determinants. Science 22: $60-62$.

Hamburger, V., and H. L. Hamilton (1951) A series of normal stages in the development of the chick embryo. J. Morphol. 88: 49-92.

Hanson, G. R., P. L. Iversen, and L. M. Partlow (1982) Preparation and partial characterization of highly purified primary cultures of neurons and non-neuronal (glial) cells from embryonic chick cerebral hemispheres and several other regions of the nervous system. Dev. Brain Res. 3: 529-545.

Hartwig, J. H., and T. P. Stossel (1975) Isolation and properties of 
actin, myosin, and a new actin-binding protein in rabbit alveolar macrophages. J. Biol. Chem. 250: 5696.

Heggeness, M. H., K. Wang, and S. J. Singer (1977) Intracellular distributions of mechanochemical proteins in cultured fibroblasts. Proc. Natl. Acad. Sci. USA 74: 3883-3887.

Kahn, A. J. (1974) An autoradiographic analysis of the time of appearance of neurons in the developing chick neural retina. Dev. Biol. 38: $30-40$.

Koteliansky, V. E., V. P. Shirinsky, G. N. Gneushev, and V. N. Smirnov (1981) Filamin, a high relative molecular mass actin-binding protein from smooth muscles, promotes actin polymerization. FEBS Lett. 136: 98-100.

Lazarides, E., and W. J. Nelson (1983) Erythrocyte and brain forms of spectrin in cerebellum: Distinct membrane-cytoskeletal domains in neurons. Science 220: 1295-1296.

Lemmon, V. (in press) Monoclonal antibodies specific for glia in the chick nervous system. Dev. Brain Res.

Lemmon, V., and G. Rieser (1983) The developmental distribution of vimentin in the chick retina. Dev. Brain Res. 11: 191-197.

Lemmon, V., B. Staros, H. E. Perry, and D. I. Gottlieb (1982) A monoclonal antibody which binds to the surface of chick brain cells and myotubes: Cell selectivity and properties of the antigen. Dev. Brain Res. 3: 349-360.

Levine, J., and M. Willard (1981) Fodrin: Axonally transported polypeptides associated with the internal periphery of many cells. J. Cell Biol. 90: 631-643.

Linser, P. J. (1985) Multiple marker analysis in the avian optic tectum reveals three classes of neuroglia and carbonic anhydrase-containing neurons. J. Neurosci. 5: 2388-2396.

Mangeat, P. H., and K. Burridge (1983) Binding of HeLa spectrin to a specific HeLa membrane fraction. Cell Motil. 3: 657-669.

McLean, I. W., and P. K. Nakane (1974) Periodate-lysine paraformaldehyde fixative: A new fixative for immunoelectron microscopy. J. Histochem. Cytochem. 22: 1077-1083.

Moscona, A. A., and P. Linser (1983) Developmental and experimental changes in retinal glia cells: Cell interactions and control of phenotype expression and stability. Curr. Topics Dev. Biol. 18: 155188.

Mose-Lansen, P. (1981) An assessment of the potential offered by two- dimensional gel electrophoresis and silver staining for developmental biology. Unpublished dissertation, Aarhus University.

Pettmann, B., J. C. Louis, and M. Sensenbrenner (1979) Morphological and biochemical maturation of neurons cultured in the absence of glial cells. Nature 281: 378-380.

Rutishauser, U. (1984) Developmental biology of a neural cell adhesion molecule. Nature 310: 549-554.

Rutishauser, U., J.-P. Thiery, R. Brackenbury, and G. M. Edelman (1978) Adhesion among neural cells of the chick embryo. III. Relationship of the surface molecule CAM to cell adhesion and the development of histotypic patterns. J. Cell Biol. 79: 371-381.

Sensenbrenner, M., and P. Mandel (1974) Behaviour of neuroblasts in the presence of glial cells, fibroblasts and meningeal cells in culture. Exp. Cell Res. 87: 159-167.

Shaw, G., M. Osborn, and K. Weber (1981) Arrangement of neurofilaments, microtubules and microfilament-associated proteins in cultures dorsal root ganglia cells. Eur. J. Cell Biol. 24: 20-27.

Snyder, C., J. Hailey, and V. Lemmon (1984) Monoclonal antibodies specific for ganglion cells in the developing chick retina. Soc. Neurosci. Abstr. 10: 757.

Stossel, T. P., J. H. Hartwig, H. L. Yin, K. S. Zaner, and O. I. Stendah (1981) Actin gelation and the structure of cortical cytoplasm. Cold Spring Harbor Symp. Quant. Biol. 46: 569-578.

Tapscott, S. J., G. S. Bennet, Y. Toyama, F. Kleinbart, and H. Holtzer (1981) Intermediate filament proteins in the development of the chick spinal cord. Dev. Biol. 86: 40-54.

Towbin, H., T. Staehelin, and J. Gordon (1979) Electrophoretic transfer of proteins from polyacrylamide gels to nitrocellulose sheets: Procedure and some applications. Proc. Natl. Acad. Sci. USA 76:43504354.

Wang, K., J. F. Ash, and S. J. Singer (1975) Filamin, a new highmolecular-weight protein found in smooth muscle and non-muscle cells. Proc. Natl. Acad. Sci. USA 72: 4483-4486.

Weihing, R. R. (1982) Purification of a HeLa cell high molecular weight actin binding protein and its identification in HeLa cell plasma membrane ghosts and intact HeLa cells. Biochemistry 22: 1839-1847.

Wulf, E., A. Deboben, F. A. Baut, H. Faulstich, and T. Wieland (1979) Fluorescent phallotoxin, a tool for the visualization of cellular actin. Proc. Natl. Acad. Sci. USA 76: 4498-4502. 